\title{
ENVIRONMENTAL SELECTION IN THE SNAIL CEPAEA VINDOBONENSIS IN THE LIKA AREA OF YUGOSLAVIA
}

\author{
J. S. JONES \\ Department of Biology, Royal Free Hospital School of Medicine, 8 Hunter Street, \\ London WCIN 1BP
}

Received 13.iii.73

\section{SUMmary}

Populations of the snail Cepaea nemoralis often show local genetic differentiations (area effects). The importance of environmental selection in controlling such patterns of gene distribution is uncertain, as some local associations of morph frequency with microclimate are not found in other populations.

The eastern European snail $C$. vindobonensis has a very simple shell polymorphism. C. vindobonensis populations in north Yugoslavia show a clear tendency for snails with reduced band pigmentation to be found in places with a warm microclimate.

This paper describes $C$. vindobonensis in another region with a similar topography. There is a very similar pattern of association of morph frequency with topography, snails with reduced band pigment being common only outside large basins which act as frost hollows.

This consistency of association with environment suggests that climatic selection is of general importance in affecting morph frequency distribution in C. vindobonensis populations.

\section{INTRODUCTION}

Some populations of the polymorphic British snail Cepaea nemoralis show a striking pattern of local genetic differentiation. Groups of populations covering a large area are characterised by a limited range of gene frequencies, while adjacent groups of populations have quite different frequencies of these genes. Clines between such " area effects" (Cain and Currey, 1963a) are often very steep, and may not coincide with a detectable environmental discontinuity. The role of environmental selection in controlling the distribution of genes in area effects is a matter of controversy. Some authors claim that environmental selection has a major effect on gene frequencies, while others emphasise the importance of random processes or the evolution of differently coadapted gene complexes in each area effect (Cain and Currey, 1963a; Clarke, 1968). Surveys of local $C$. nemoralis populations have not yet provided an unequivocal answer to the problem of the importance of environmental selection in controlling gene frequencies in area effects.

C. vindobonensis is an eastern European snail which has a much simpler system of shell polymorphism than $C$. nemoralis. Variation is limited to the number of bands on the shell (usually four or five) and to differences in the intensity of band pigmentation (dark and fully pigmented, or a light straw colour known as "faint banding"). Only one population of this species has been investigated (Jones, 1973a). This lives in the Velebit Mountains of north Yugoslavia. It shows a striking association of morph frequency with topography. Faint banded shells occur only away from the extensive basins surrounded by mountains which are characteristic of this region. Not all 
hillside samples contain faint banded shells, but this morph reaches high frequencies only on the mountain slopes. This association is due at least in part to climatic selection. The basins act as frost hollows on clear nights, so that their mean minimum night temperature is considerably lower than that of the hillsides. Direct measurement with temperature probes combined with behavioural experiments shows that dark-coloured snails absorb more solar energy than do faint banded, and that because of this the time to activity of dormant fully pigmented snails in the sun is considerably less than that of faint banded (Jones, 1973a). Fully pigmented snails can therefore attain a temperature suitable for activity in the early morning sun after a temperature inversion more rapidly than can faint banded. Faint banded snails are presumably at a corresponding advantage in the warmer conditions of the mountain slopes.

Surveys of different $C$. nemoralis populations have often shown a lack of consistency in the apparent associations of morph frequency with habitat which make it difficult to identify any environmental selective factors. For example, brown-shelled nemoralis on the Marlborough Downs are found preferentially in frost hollows, while on the Larkhill Artillery Ranges nearby this does not appear to be the case (Cain and Currey, 1963a, b). Similarly, the upper parts of some Pyrenean valleys have a very high frequency of unbanded $C$. nemoralis (Arnold, 1968), but in nearby valleys unbanded shells are almost absent from the highest $C$. nemoralis populations (Jones, in preparation).

This paper describes a second Yugoslav $C$. vindobonensis population living in the drainage area of the river Lika, around the town of Gospić. The Lika area is south of that previously studied.

\section{ThE AREA STUdied}

Like the Gacka area, the Lika region consists of high limestone mountains surrounding level basins (fig. 1). The mountains are higher than in the Gacka (up to $1750 \mathrm{~m}$ ), and the basins considerably more extensive, some being as much as $15 \mathrm{~km}$ wide. The floors of most of the basins are at a greater elevation than are those of the major Gacka basins and they are often less level. The vegetation is generally similar to that previously described (Jones, $1973 a, b)$, although there is less cultivation and scrubland is more widespread than in the Gacka region.

\section{Distribution of SNAILS AND of phenotypes}

Cepaea was less common than in the area previously studied, and there was a higher frequency of unmixed colonies of $C$. nemoralis or $C$. vindobonensis. Habitats were similar to those in the Gacka region, most samples originating from thorn hedges or from open mixed deciduous scrub. The full data are extensive and have been published elsewhere (Jones, 1973c). This survey was carried out during the summers of 1966, 1968 and 1972.

There are differences in overall morph frequency between the Lika and Gacka regions, and considerable microgeographical differentiation within the Lika populations themselves. The frequency of shells with faint bands is 16.4 per cent in the Lika, compared to 11.2 per cent in the Gacka; of shells with the second band missing 9.0 per cent $(2 \cdot 7$ per cent $)$; and of shells with 


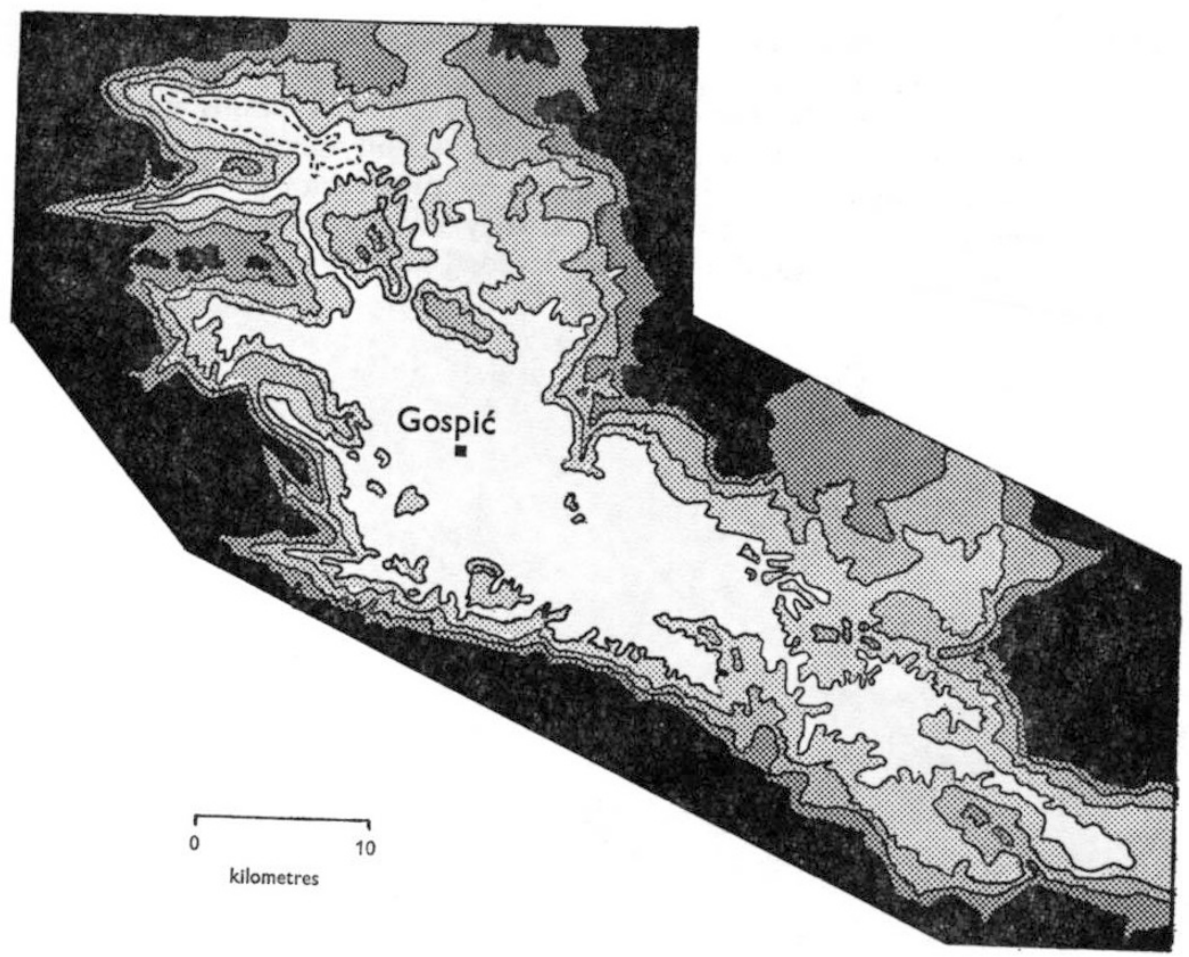

FIG. 1.- Ine lika area. Contours al juv, uve, ivu, ouv anu juv 11.

bands fused together $8 \cdot 1$ per cent $(19 \cdot 2$ per cent). The pattern of microgeographical distribution of phenotypes is similar to that found in the Gacka populations of $C$. vindobonensis and in many British $C$. nemoralis populations. Each morph reaches high frequencies in some populations, but is absent from others. This is most marked for the frequency of faint banded shells, which are common in some parts of the Lika area but are not found in others (fig. 2).

\section{Associations with environment}

No associations of morph frequency with background vegetation were obvious. As in the Gacka region, faint banded snails occur preferentially on the mountain slopes, and are much rarer in the basins. With one or two minor exceptions this is true for the eight separate basins in the Lika area. Fig. 3 shows the association between the frequency of faint bands and height of the sample above the nearest basin. There is no apparent association between the frequency of shells with missing bands or with bands fused together and topography.

\section{Discussion}

The pattern of distribution of morph frequencies in the Lika C. vindobonensis populations is similar to that found in the Gacka populations. This is particularly noticeable for the frequency of faint bands. The association 
of faint banded snails with hillsides is not as precise as in the Gacka area, but the general pattern of association is very similar. Similar selective mechanisms are probably involved in both survey regions. The basins act as frost hollows, in which cold air accumulates at night. Fully pigmented snails are able to reach a temperature suitable for activity after a temperature inversion more rapidly than can faint-banded, as they have a greater efficiency of energy absorption from sunshine. Faint-banded snails are at a corresponding

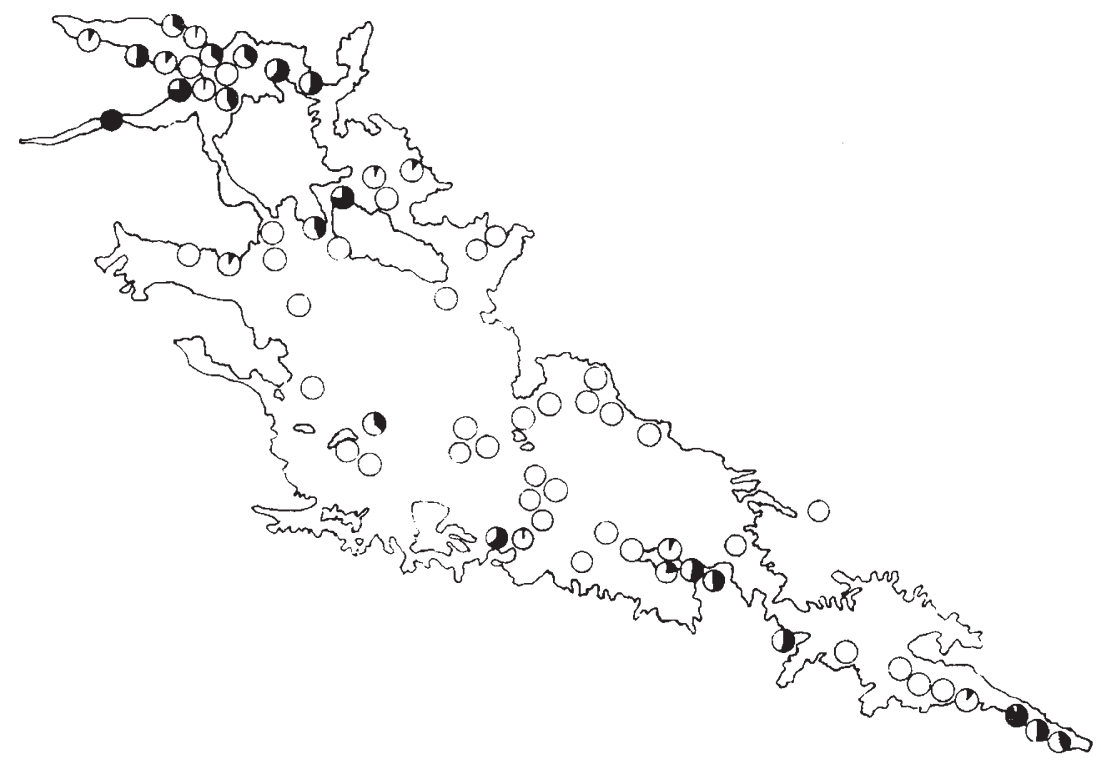

FIg. 2.-Distribution of faint banded C. vindobonensis (black sector) in the Lika area. $600 \mathrm{~m}$ contour also shown.

advantage in the warmer conditions of the mountain slopes. Less direct evidence is available on the development of temperature inversions in the Lika basins than in the basins of the Gacka region, but a comparison of minimum temperatures at Gospic $(564 \mathrm{~m})$ and Ostarije in the surrounding mountains $(924 \mathrm{~m})$ shows that temperature inversions are common, and that the basin floor may reach a temperature as much as $17^{\circ} \mathrm{C}$. below that of the surrounding mountain slopes (Anon., 1944). It is, of course, true that hillsides differ from basins in a number of ways-soil depth, aridity, exposure etc.-which might also affect gene frequency. The physiological experiments described by Jones (1973a), however, suggest that temperature is one important selective agent. There is an indication that in these populations steepness of slope also affects the frequency of faint bands, so that populations from steep hillsides have a higher frequency of this morph than do those from gentler slopes with the same height above a basin. This pattern of distribution may be due to more rapid shedding of cold air by steep slopes, or perhaps to other variables such as their greater aridity. It is not possible to identify an environmental factor which affects the frequency of shells with missing bands or with bands fused together.

There is considerable consistency between the pattern of association of gene frequencies with environment in these populations and those previously 


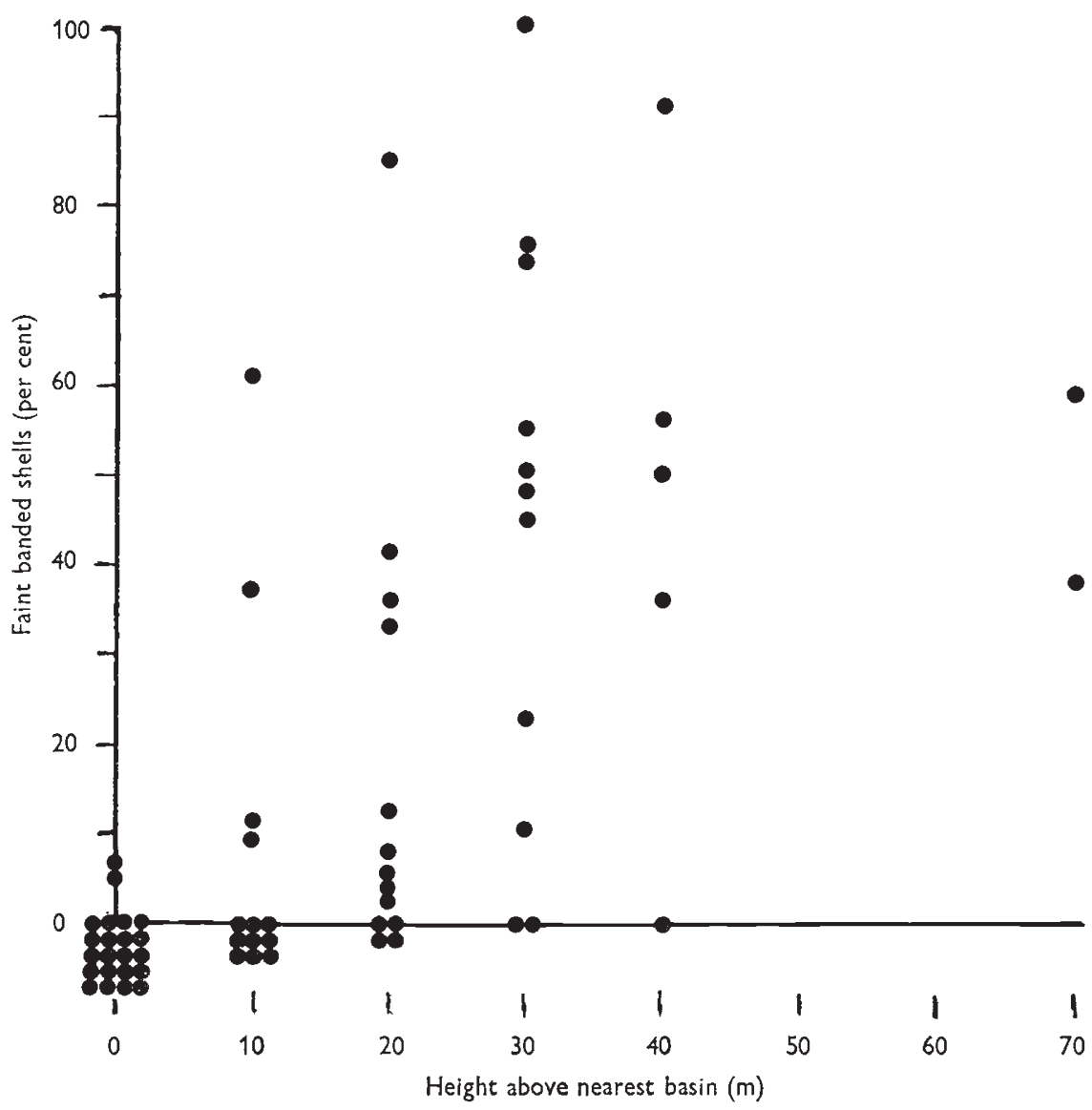

Fxc. 3.-Association between frequency of faint banded shells and height above nearest basin in $C$. vindobonensis in the Lika area.

described. This similarity between populations living in different areas suggests that environmental selection, one component of which is associated with microclimate, may be of general importance in controlling the frequencies of some genes in $C$. vindobonensis populations.

Acknowledgments. - I am grateful to the Yugoslav Academy of Sciences, the Croatian Commission for Cultural Relations with Foreign Countries, and the Croatian Institute for Nature Protection for giving us permission to carry out research in Yugoslavia, and to the numerous colleagues who assisted in the field. This research was supported by a grant from the Royal Society.

\section{REFERENCES}

ANONYmous. 1944. Jugoslavia. BR 493. Geographical Handbook Series, London.

ARNOLD, R. W. 1968. Studies on Cepaea. VII. Climatic selection in Cepaea nemoralis (L.) in the Pyrenees. Phil. Trans. Roy. Soc. Lond., B, 253, 549-593.

cain, A. J., AND Currey, J. D. 1963a. Area effects in Cepaea. Phil. Trans. Roy. Soc. Lond., B, $246,1-81$.

$32 / 2-\mathrm{L} 2$ 
CAIN, A. J., AND CURREY, J. D. 1963b. Area effects in Cepaea on the Larkhill Artillery Ranges, Salisbury Plain. 7. Linnaean Soc. Lond. (Zool.), 45, 1-15.

CLARKE, B. c. 1968. Balanced polymorphism and regional differentiation in land snails. In Evolution and Environment, ed. E. T. Drake, pp. 351-368. Yale University Press, New Haven.

JONEs, J. s. 1973a. Ecological genetics and natural selection in molluscs. Science, 182, 546-552.

JONEs, J. s. 1973b. The genetic structure of a southern peripheral population of the snail Cepaea nemoralis (L.). Proc. Roy. Soc. Lond., B, 183, 371-384.

JONEs, J. s. 1973c. Morph frequencies in populations of the snail Cepaea vindobonensis (Pf.) from the Lika area of Yugoslavia and from the Dobrogea (Romania). Evolutionary Genetics Res. Rep., 12, 1-11. Filed at the National Lending Library for Science and Technology, Boston Spa, Yorkshire, England. 